This item was submitted to Loughborough's Research Repository by the author.

Items in Figshare are protected by copyright, with all rights reserved, unless otherwise indicated.

\title{
Influences of car body vertical flexibility on ride quality of passenger railway vehicles
}

PLEASE CITE THE PUBLISHED VERSION

PUBLISHER

(C) Professional Engineering Publishing / IMechE

\section{VERSION}

VoR (Version of Record)

\section{LICENCE}

CC BY-NC-ND 4.0

\section{REPOSITORY RECORD}

Zhou, J., Roger M. Goodall, L. Ren, and H. Zhang. 2019. "Influences of Car Body Vertical Flexibility on Ride Quality of Passenger Railway Vehicles". figshare. https://hdl.handle.net/2134/5479. 
This item was submitted to Loughborough's Institutional Repository (https://dspace.lboro.ac.uk/) by the author and is made available under the following Creative Commons Licence conditions.

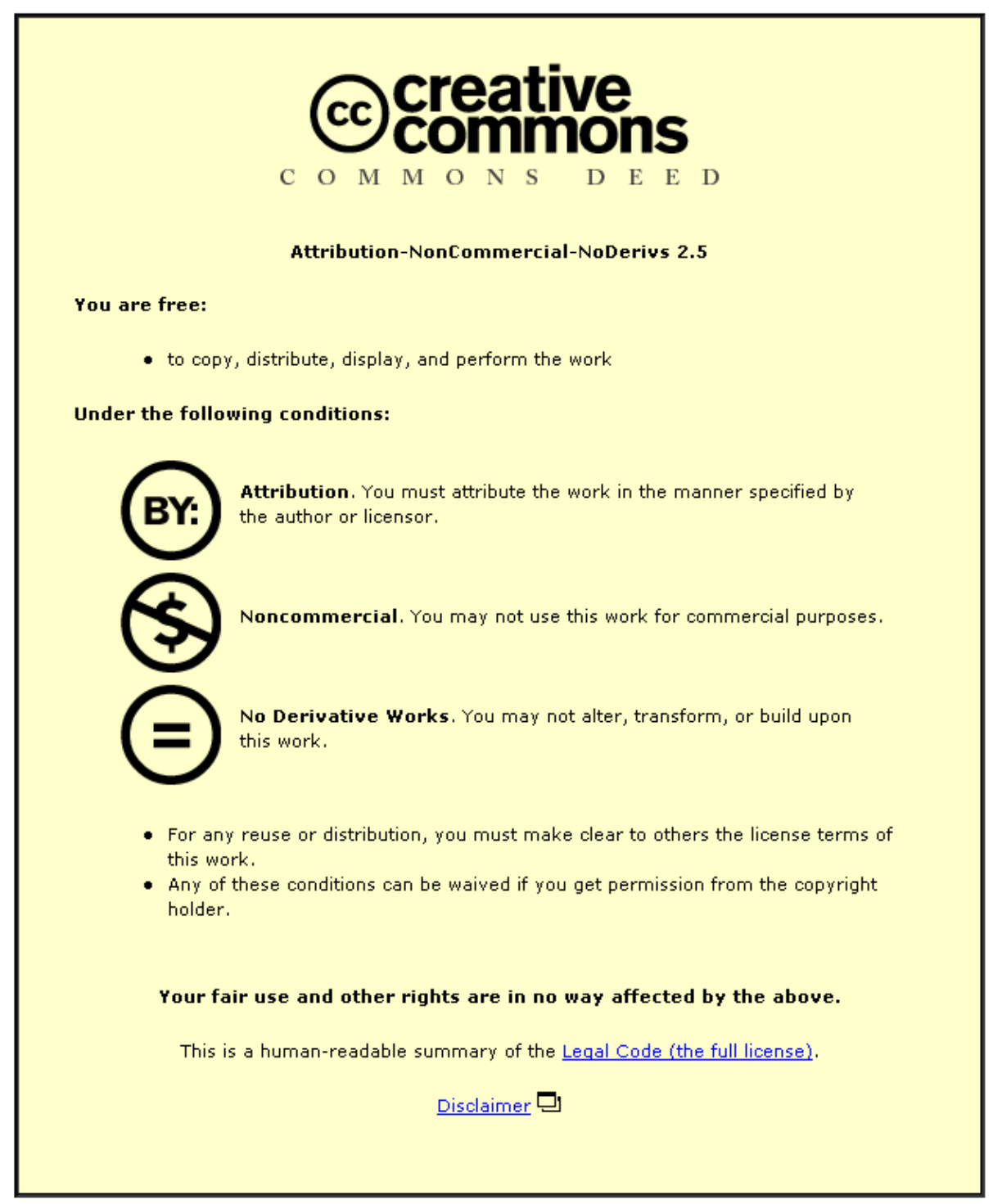

For the full text of this licence, please go to: http://creativecommons.org/licenses/by-nc-nd/2.5/ 


\title{
Influences of car body vertical flexibility on ride quality of passenger railway vehicles
}

\author{
J Zhou $^{1 *}$, R Goodall ${ }^{2}$, L Ren $^{1}$, and H Zhang ${ }^{3}$ \\ ${ }^{1}$ Railway and Urban Rail Transit Research Institute, Tongji University, Shanghai, People's Republic of China \\ ${ }^{2}$ Department of Electronic and Electrical Engineering, Loughborough University, Loughborough, UK \\ ${ }^{3}$ Technology Centre of SiFang Locomotive and Rolling Stock Limited Co., Qingdao, People's Republic of China
}

The manuscript was received on 29 January 2009 and was accepted after revision for publication on 30 April 2009.

DOI: 10.1243/09544097JRRT272

\begin{abstract}
To study the influences of carbody vertical stiffness on vehicle ride quality, a vertical model of railway passenger vehicles, which includes the carbody flexible effects and all vertical rigid modes, is built. With the model and the covariance method, the requirements for the carbody bending frequency are researched. The results show that when the stiffness of a carbody decreases to certain frequencies there are significant vibrations in the carbody, although structural damping provided by a fully equipped carbody will help attenuate the vibration to some extent. A simple way to avoid resonant vibration is to increase the bending frequencies of a carbody: the higher the vehicle running speed, the higher carbody stiffness could be required. However, there are practical limitations to such an increase and the method used in this study can readily obtain the lowest bending frequency required by vehicle ride quality. Finally, the geometric filtering phenomenon and its influences on the carbody resonant flexural vibration are analysed. Results show that it is this phenomenon rather than the natural vibrations of bogie bounce that most strongly influences the resonant flexural vibration of a railway carbody.
\end{abstract}

Keywords: railway vehicle, carbody flexibility, ride quality, modal parameter

\section{INTRODUCTION}

Nowadays, three-dimensional design softwares, finite element method (FEM) analysis tools, and aluminium alloy profiled materials are widely used in railway industry, which makes light structures no longer a 'mission impossible' [1]. Demands by transportation service providers to maximize usage of the limited axle loads also compel the railway industry to adopt the light structure design. But light weight design, while satisfying the requirements of strength and crashworthiness, is achieved usually at a cost of significant decrease in structural stiffness and consequently the decrease of bending frequencies. Thereby, the traditional rigid-body models are no longer suitable to predict the ride performances accurately. By incorporating the FEM carbody model into multi-body

\footnotetext{
*Correspondingauthor: Railway and Urban Mass Transit Research, Tongji University, Building F, 2nd floor, Cao An Gong Lu 4800, Shanghai 201804, People's Republic of China.

email:jinsong.zh@gmail.com; jinsong.zhou@tongji.edu.cn
}

vehicle model, Carlbom has studied the influences of carbody flexibility on ride quality and vehicle dynamics through measurements and simulations $[2,3]$. To reduce the finite-element model and make simulation more efficient, he presented four criteria, i.e. modal participation factors, mode contribution factors, excitation spectra, and comfort filters, to select which carbody eigenmodes have the greatest contribution upon ride quality. Diana also has demonstrated that it is essential to consider the carbody flexibility to reproduce ride comfort of railway vehicles [4]. He proposed using the modal superposition method to account for the flexibility to carbody and bogies. Although a total of 33 modes within $5-20 \mathrm{~Hz}$ were considered, with global and local mode shapes ranging from carbody bending, torsion, and roof/floor/side/walls vibration, numerical and experimental comparisons of the researched vehicle showed that the mode which most significantly influences carbody dynamic behaviour was the first bending mode.

To suppress the carbody flexural vibration, many active control schemes have been proposed for the secondary suspensions or on carbody structures. 
Hac [5] and Wu and Zeng [6] studied the effects of active and semi-active secondary suspensions on the vibration control of a vehicle system with a flexible carbody. Foo and Goodall [7] proposed to utilize both active secondary suspensions and an active dynamic vibration absorber suspended under the carbody chassis to suppress simultaneously the flexible and rigid mode vibration. Takigami and Tomioka [8] embedded piezoelectric elements on the chassis of a 1:5 scale Shinkansen vehicle model, and tested the effectiveness of their configuration and control methods in terms of the reduction in the carbody flexural vibration. Later, Schandl et al. [9] mounted piezo-stack actuators on longitudinal beams of a carbody underframe to increase damping of the three eigenmodes, i.e. vertical bending, diagonal distortion, and torsion, which were considered the most important modes with respect to carbody vertical vibration behaviour and verified the control scheme by a co-simulation with SIMPACK ${ }^{\circledR}$ and MATLAB $^{\circledR} /$ Simulink. Because the railway industry is relatively conservative, the costs and complexity of active techniques still pose a big problem for the railway industry, which therefore hampers their wide applications.

A railway vehicle is a large, complex dynamic system, which becomes even more complex when considering the flexibility of its components. Carbody global and local modes, such as bending, torsion, diagonal torsion modes, and local deformations on floor, contribute differently to carbody vertical vibration behaviour according to their specific structures. Bogie pitch and vehicle longitudinal vibrations will also influence the carbody bending vibrations. However, all studies agree that the carbody bending modes are the most important factors that significantly influence the vertical ride quality. Suzuki first simplifies the carbody as an elastically supported three-piece beam and studied the influences of the carbody bending modes on ride quality $[\mathbf{1 0}]$. In the current study a different beam model is used, with the intention to deal with problems that have not been rigorously addressed before, practical issues such as how the carbody flexural resonant vibration happens and what is the lowest requirement of the bending mode frequency for a fully equipped vehicle before active techniques are required. An additional contribution is an analysis of the geometric filtering phenomenon $[\mathbf{1 1}, \mathbf{1 2}]$ and its influences on the carbody resonant vibration, which has not previously been directly studied in the context of carbody flexural vibrations.

Of course the effect of the more complex modes is necessary for detailed design, but the characteristics of such modes are vehicle specific, which detracts from the generality of the scientific conclusions. Therefore, the use of a simpler model provides a better general understanding of the above-mentioned effects.

\section{A VERTICAL THEORETICAL MODEL WITH CARBODY FLEXIBILITY}

When analysing the influences of carbody bending stiffness on vehicle vertical ride quality, a finiteelement model of a carbody could be built and incorporated into a SIMPACK or ADAMS/rail ${ }^{\circledR}$ nonlinear model to do detailed and accurate analysis $[3,4,13]$. However, changing bending frequencies of a FEM vehicle model to a particular value is comparatively difficult. Thereby, in this study, the carbody is modelled as a simple uniform Euler-Bernoulli beam supported on secondary suspensions as shown in Fig. 1, in which only vertical vibrations of the carbody, i.e. bounce, pitch, and flexible bending modes are considered. Each of the two bogies has the same freedoms as the carbody rigid modes, i.e. bounce and

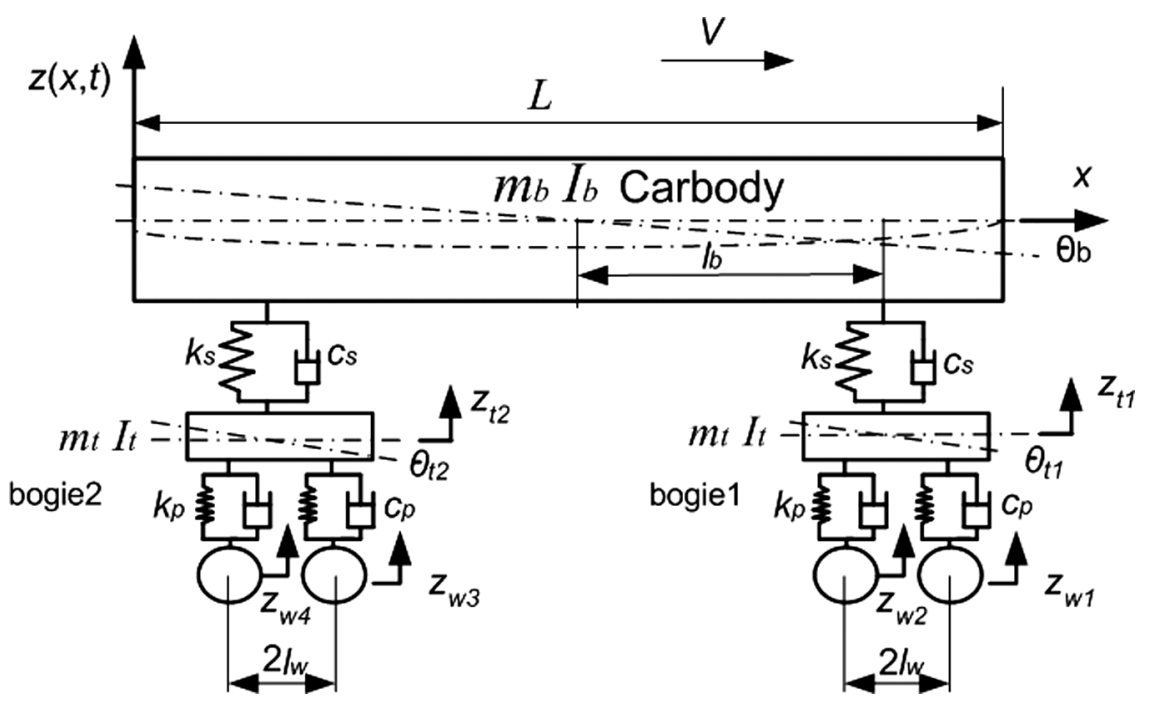

Fig. 1 Vertical theoretical model of railway passenger vehicle 
pitch modes. It is assumed that no wheel jump happens when the vehicle runs on track, which means the wheelsets vertical movements are exactly the same as the track irregularity. Coordinates definition and some dimensions are shown in Fig. 1.

When the vertical displacement of carbody being expressed as $z(x, t)$, the appropriate partial differential equation of the carbody is

$$
\begin{aligned}
E I & \frac{\partial^{4} z(x, t)}{\partial x^{4}}+\mu I \frac{\partial^{5} z(x, t)}{\partial t \partial x^{4}}+\rho \frac{\partial^{2} z(x, t)}{\partial t^{2}} \\
& =P_{1} \delta\left(x-l_{1}\right)+P_{2} \delta\left(x-l_{2}\right)
\end{aligned}
$$

where $P_{1}$ is the force acted by bogie 1 secondary suspension and $P_{2}$ is that of bogie 2. $P_{1}$ and $P_{2}$ are

$$
\left.\begin{array}{l}
P_{1}=-k_{\mathrm{s}}\left[z\left(l_{1}, t\right)-z_{t 1}\right]-c_{\mathrm{s}}\left[\dot{z}\left(l_{1}, t\right)-\dot{z}_{t 1}\right] \\
P_{2}=-k_{\mathrm{s}}\left[z\left(l_{2}, t\right)-z_{t 2}\right]-c_{\mathrm{s}}\left[\dot{z}\left(l_{2}, t\right)-\dot{z}_{t 2}\right]
\end{array}\right\}
$$

To solve the partial differential equation (1), the variable separation method is usually applied. It is assumed that the shape function and modal coordinate of $i$ th mode are $Y_{i}(x)$ and $q_{i}(t)$, respectively. When the rigid modes are included with the flexible modes in $z(x, t)$, the first mode of the carbody is chosen as the bounce of rigid mode and its shape function is taken as $Y_{1}(x)=1$. The second mode is the pitch and its shape function is $Y_{2}(x)=L / 2-x$ accordingly under the coordinate definition as in Fig. 1. When $n$ modes are considered, the vertical displacement of the carbody can be written as

$$
z(x, t)=z_{\mathrm{b}}(t)+\left(\frac{L}{2}-x\right) \theta_{\mathrm{b}}(t)+\sum_{i=3}^{n} Y_{i}(x) q_{i}(t)
$$

while for $i>2$, the shape functions are taken as

$$
\begin{aligned}
Y_{i}(x)= & \operatorname{ch} \beta_{i} x+\cos \beta_{i} x-\frac{\operatorname{ch} \lambda_{i}-\cos \lambda_{i}}{\operatorname{sh} \lambda_{i}-\sin \lambda_{i}} \\
& \times\left(\operatorname{sh} \beta_{i} x+\sin \beta_{i} x\right)
\end{aligned}
$$

where $\lambda_{i}$ and $\beta_{i}$ satisfy

$$
1-\operatorname{ch} \lambda_{i} \cos \lambda_{i}=0, \quad \beta_{i}=\frac{\lambda_{i}}{L}
$$

By substituting equation (3) into equation (1) and integrating along the length of carbody, considering the orthogonality of shape functions, one obtains

$$
\begin{aligned}
& m_{\mathrm{b}} \ddot{z}_{\mathrm{b}}(t)=P_{1}+P_{2} \\
& I_{\mathrm{b}} \ddot{\theta}_{\mathrm{b}}(t)=P_{1}\left(\frac{L}{2}-l_{1}\right)+P_{2}\left(\frac{L}{2}-l_{2}\right) \\
& \ddot{q}_{i}(t)+\frac{\mu I \beta_{i}^{4}}{\rho} \dot{q}_{i}(t)+\frac{E I \beta_{i}^{4}}{\rho} q_{i}(t)=\frac{Y_{i}\left(l_{1}\right)}{m_{\mathrm{b}}} P_{1} \\
& \quad+\frac{Y_{i}\left(l_{2}\right)}{m_{\mathrm{b}}} P_{2}, \quad i=3,4, \ldots, n
\end{aligned}
$$

Let

$$
\frac{E I \beta_{i}^{4}}{\rho}=\omega_{i}^{2}, \quad \frac{\mu I \beta_{i}^{4}}{\rho}=2 \xi_{i} \omega_{i}
$$

Hence, the equation (8) is given by

$$
\begin{aligned}
& \ddot{q}_{i}(t)+2 \xi_{i} \omega_{i} \dot{q}_{i}(t)+\omega_{i}^{2} q_{i}(t) \\
& \quad=\frac{Y_{i}\left(l_{1}\right)}{m_{\mathrm{b}}} P_{1}+\frac{Y_{i}\left(l_{2}\right)}{m_{\mathrm{b}}} P_{2}, \quad i=3,4, \ldots, n
\end{aligned}
$$

Substitute equation (3) into equation (2), yields

$$
\begin{aligned}
& P_{1}=-k_{\mathrm{s}}\left[z_{\mathrm{b}}(t)+\left(\frac{L}{2}-l_{1}\right) \theta(t)\right. \\
&\left.+\sum_{m=3}^{n} Y_{m}\left(l_{1}\right) q_{m}(t)-z_{t 1}\right] \\
&-c_{\mathrm{s}}\left[\dot{z}_{\mathrm{b}}(t)+\left(\frac{L}{2}-l_{1}\right) \dot{\theta}(t)\right. \\
&\left.+\sum_{m=3}^{n} Y_{m}\left(l_{1}\right) \dot{q}_{m}(t)-\dot{z}_{t 1}\right] \\
& P_{2}=-k_{\mathrm{s}}\left[z_{\mathrm{b}}(t)+\left(\frac{L}{2}-l_{2}\right) \theta(t)\right. \\
&\left.+\sum_{m=3}^{n} Y_{m}\left(l_{2}\right) q_{m}(t)-z_{t 2}\right] \\
&-c_{\mathrm{s}}\left[\dot{z}_{\mathrm{b}}(t)+\left(\frac{L}{2}-l_{2}\right) \dot{\theta}(t)\right. \\
&\left.+\sum_{m=3}^{n} Y_{m}\left(l_{2}\right) \dot{q}_{m}(t)-\dot{z}_{t 2}\right]
\end{aligned}
$$

The vibration equations of the two bogies in the vehicle system can be implemented by using normal Newtonian mechanics as

$$
\begin{aligned}
m_{\mathrm{t}} \ddot{z}_{t 1}= & -k_{\mathrm{s}}\left[z_{t 1}-z\left(l_{1}, t\right)\right]-c_{\mathrm{s}}\left[\dot{z}_{t 1}-\dot{z}\left(l_{1}, t\right)\right] \\
& -k_{\mathrm{p}}\left(z_{t 1}-l_{\mathrm{w}} \theta_{t 1}-z_{w 1}\right) \\
& -c_{\mathrm{p}}\left(\dot{z}_{t 1}-l_{\mathrm{w}} \dot{\theta}_{t 1}-\dot{z}_{w 1}\right)-k_{\mathrm{p}}\left(z_{t 1}+l_{\mathrm{w}} \theta_{t 1}-z_{w 2}\right) \\
& -c_{\mathrm{p}}\left(\dot{z}_{t 1}+l_{\mathrm{w}} \dot{\theta}_{t 1}-\dot{z}_{w 2}\right) \\
I_{\mathrm{t}} \ddot{\theta}_{t 1}= & l_{\mathrm{w}} k_{\mathrm{p}}\left(z_{t 1}-l_{\mathrm{w}} \theta_{t 1}-v z_{w 1}\right)+l_{\mathrm{w}} c_{\mathrm{p}}\left(\dot{z}_{t 1}-l_{\mathrm{w}} \dot{\theta}_{t 1}-\dot{z}_{w 1}\right) \\
& -l_{\mathrm{w}} k_{\mathrm{p}}\left(z_{t 1}+l_{\mathrm{w}} \theta_{t 1}-z_{w 2}\right) \\
& -l_{\mathrm{w}} c_{\mathrm{p}}\left(\dot{z}_{t 1}+l_{\mathrm{w}} \dot{\theta}_{t 1}-\dot{z}_{w 2}\right) \\
m_{\mathrm{t}} \ddot{z}_{t 2}= & -k_{\mathrm{s}}\left[z_{t 2}-z\left(l_{2}, t\right)\right]-c_{\mathrm{s}}\left[\dot{z}_{t 2}-\dot{z}\left(l_{2}, t\right)\right] \\
& -k_{\mathrm{p}}\left(z_{t 2}-l_{\mathrm{w}} \theta_{t 2}-z_{w 3}\right) \\
& -c_{\mathrm{p}}\left(\dot{z}_{t 2}-l_{\mathrm{w}} \dot{\theta}_{t 2}-\dot{z}_{w 3}\right)-k_{\mathrm{p}}\left(z_{t 1}+l_{\mathrm{w}} \theta_{t 1}-z_{w 4}\right) \\
& -c_{\mathrm{p}}\left(\dot{z}_{t 1}+l_{\mathrm{w}} \dot{\theta}_{t 1}-\dot{z}_{w 4}\right) \\
I_{\mathrm{t}} \ddot{\theta}_{t 2}= & l_{\mathrm{w}} k_{\mathrm{p}}\left(z_{t 2}-l_{\mathrm{w}} \theta_{t 2}-z_{w 3}\right) \\
& +l_{\mathrm{w}} c_{\mathrm{p}}\left(\dot{z}_{t 2}-l_{\mathrm{w}} \dot{\theta}_{t 2}-\dot{z}_{w 3}\right) \\
& -l_{\mathrm{w}} k_{\mathrm{p}}\left(z_{t 2}+l_{\mathrm{w}} \theta_{t 2}-z_{w 4}\right) \\
& -l_{\mathrm{w}} c_{\mathrm{p}}\left(\dot{z}_{t 2}+l_{\mathrm{w}} \dot{\theta}_{t 2}-\dot{z}_{w 4}\right)
\end{aligned}
$$


Table 1 Typical vehicle parameters

\begin{tabular}{llll}
\hline$m_{b}$ & $26000 \mathrm{~kg}$ & $k_{\mathrm{s}}$ & $0.45 \times 10^{6} \mathrm{~N} / \mathrm{m}$ \\
$I_{b}$ & $1.274 \times 10^{6} \mathrm{~kg} \mathrm{~m}^{2}$ & $c_{\mathrm{s}}$ & $60 \times 10^{3} \mathrm{~N} \mathrm{~s} / \mathrm{m}$ \\
$m_{t}$ & $2600 \mathrm{~kg}$ & $k_{\mathrm{p}}$ & $2.40 \times 10^{6} \mathrm{~N} / \mathrm{m}$ \\
$I_{t}$ & $1423.8 \mathrm{~kg} \mathrm{~m}^{2}$ & $c_{\mathrm{p}}$ & $30 \times 10^{6} \mathrm{~N} \mathrm{~s} / \mathrm{m}$ \\
$\omega_{3}$ & $12.3 \times 2 \pi \mathrm{rad} / \mathrm{s}$ & $l_{\mathrm{b}}$ & $8.75 \mathrm{~m}$ \\
$\xi_{3}$ & $1.5 \%$ & $l_{\mathrm{w}}$ & $1.25 \mathrm{~m}$ \\
$\omega_{4}$ & $17.0 \times 2 \pi \mathrm{rad} / \mathrm{s}$ & $L$ & $24.5 \mathrm{~m}$ \\
$\xi_{4}$ & $1.5 \%$ & & \\
\hline
\end{tabular}

Table 2 The vehicle rigid mode characteristics

\begin{tabular}{lcl}
\hline Mode shape & $\begin{array}{l}\text { Damped } \\
\text { frequency }(\mathrm{Hz})\end{array}$ & Damping ratio \\
\hline Carbody bounce & 0.86 & 0.348 \\
Carbody pitch & 1.04 & 0.440 \\
Bogie bounce & 5.95 & 0.534 \\
Bogie pitch & 10.29 & 0.454 \\
\hline
\end{tabular}

Writing equations (6) to (8) and (13) to (16) in matrix form gives

$$
\mathbf{M} \ddot{y}+\mathbf{C} \dot{y}+\mathbf{K} y=\mathbf{D}_{\mathbf{w}} z_{w}+\mathbf{D}_{\mathbf{d w}} \dot{z}_{w}
$$

in which $\mathbf{M}, \mathbf{C}$, and $\mathbf{K}$ are the inertia, damping, and stiffness matrices, respectively, and $\mathbf{D}_{\mathbf{w}}, \mathbf{D}_{\mathbf{d w}}$ are the track displacement and velocity input matrices.

The parameters of a typical high-speed passenger vehicle are shown in Table 1, in which just two flexible modes are included - the first symmetric mode and the first asymmetric mode. And its main rigid mode parameters of the vehicle are shown in Table 2.

\section{TRACK EXCITATION AND RIDE QUALITY ASSESSMENT}

\subsection{Track irregularity spectrum}

Because the vibration problems of high-speed railway vehicles are more prominent, this study uses the highspeed vertical track irregularity PSD as system inputs, which is described in spatial domain as [14]

$$
S_{\mathrm{v} \Omega}(\Omega)=\frac{A_{\mathrm{v}} \Omega_{\mathrm{c}}^{2}}{\left(\Omega^{2}+\Omega_{\mathrm{r}}^{2}\right)\left(\Omega^{2}+\Omega_{\mathrm{c}}^{2}\right)}
$$

Before it is applied to response analysis, the equation (18) has to be transformed into a time domain PSD with the following equation

$$
S_{\omega}(\omega)=\frac{S_{\Omega}(\omega / V)}{V}
$$

where $S_{\Omega}$ and $S_{\omega}$ are the track irregularity PSDs in spatial and time domain, respectively. So the vertical track

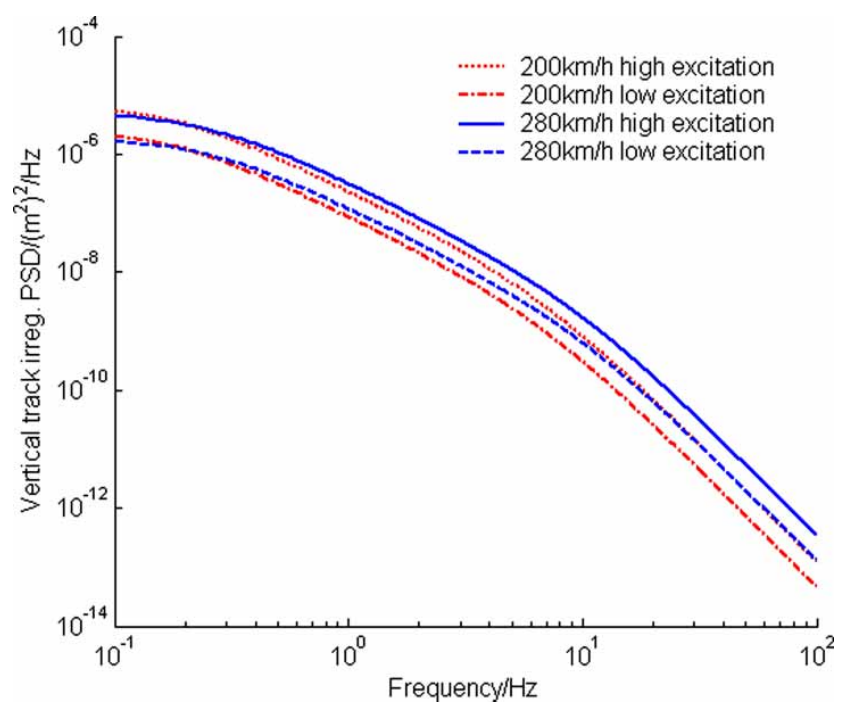

Fig. 2 High-speed high and low excitation track irregularity PSD

irregularity PSD in time domain can be obtained by

$$
S_{\mathrm{v} \omega}(\omega)=\frac{A_{\mathrm{v}} \Omega_{\mathrm{c}}^{2} V^{3}}{\omega^{4}+\left(\Omega_{\mathrm{c}}^{2}+\Omega_{\mathrm{r}}^{2}\right) V^{2} \omega^{2}+\Omega_{\mathrm{r}}^{2} \Omega_{\mathrm{c}}^{2} V^{4}}
$$

The high-speed high and low excitation track unevenness PSDs are illustrated in Fig. 2. It can be seen that the track unevenness PSDs in time domain will become 'whiter' with the increase of running speed, i.e. the track excitation power decreases for the frequencies lower than about $0.25 \mathrm{~Hz}$ and increases on higher frequencies. Also curvatures of the PSD lines become smaller at higher speeds.

\subsection{Sperling index computation}

Ride index, which is used to connect subjective comfort feelings of majority passengers with the objective physical variables of running vehicles, is a necessary tool to assess and optimize vehicle suspensions. There is a variety of ride index criteria used in many countries and their relationships and evaluation methods are presented by Kim et al. [15]. Using Kim's research, one can easily change one kind of ride indices to another. Though UIC513R and ISO2631 were introduced in the mid-1990s and are used on some occasions, China still mainly uses Sperling index to evaluate the vibration quality of a railway vehicle because it is widely familiar by the railway industry. In this study, the covariance method $[\mathbf{1 6}, \mathbf{1 7}]$ is used to calculate the Sperling index.

Covariance analysis relies on the Lyapunov matrix stability equation. It consists of two stages: first, building the state space equations of a stable dynamic system, and second, the solution of the Lyapunov equation. To get the Sperling index directly with the covariance method, the track irregularity shaping filter and perception filter have to be designed at first. 
With the equation (20) and the spectrum decomposition theory, the shaping filter of the track vertical unevenness is obtained as

$$
G_{\mathrm{v}}(s)=\frac{\Omega_{\mathrm{c}} \sqrt{A_{\mathrm{v}} V^{3}}}{s^{2}+\left(\Omega_{\mathrm{r}}+\Omega_{\mathrm{c}}\right) V s+\Omega_{\mathrm{r}} \Omega_{\mathrm{c}} V^{2}}
$$

Other track spectra that satisfy the requirements of the spectrum decomposition theory can also be designed to their own shaping filters.

The vertical perception filter for Sperling index is $[\mathbf{1 8}]$

$$
G_{\mathrm{s}}(s)=\frac{0.588\left(0.0062 s^{2}+0.2200 s\right)}{1.4836 \times 10^{-4} s^{3}+0.0070 s^{2}+0.2488 s+1}
$$

Transforming the equations (17), (21), and (22) into state space equations and combining them together, a so-called 'track-vehicle-human' unified model can be formed, with which and by solving a Lyapunov equation the perception-filtered RMS values of system responses and Sperling indices can be obtained after simple processing [19]. If ISO 2631 indices are to be calculated, one can design the perception filter according to the international standard ISO 2631-1 $[20]$, or directly use the results in reference $[\mathbf{2 1}]$. The advantages of using the covariance method are that there is no need to transform between time and frequency domain, and it only uses matrix operations to get the ride indices without having to select integration steps in time domain when computing the ride index, so the computation is indeed very fast.

\section{RESULTS AND DISCUSSIONS}

\subsection{Frequency response}

When only considering the first two flexible carbody modes, using original values for the typical high-speed vehicle parameters shown in Table 1 and a vehicle running speed of $200 \mathrm{~km} / \mathrm{h}$, acceleration PSDs at the centre of carbody and on the floor above the centre of bogie are shown in Figs 3 and 4, which show that the first bending frequency of carbody accounts for the largest percentage of carbody flexible vibration power.

\subsection{Ride quality evaluation}

Since the first-order bending frequency of a fully equipped railway vehicle has significant vibration power as shown in Figs 3 and 4, the Sperling indices are evaluated in Figs 5 and 6 when only the frequency and damping ratio of the first-order bending mode are changed and other parameters in Table 1 remain the same, and the vehicle velocity is $200 \mathrm{~km} / \mathrm{h}$. Results show that when the carbody bending frequency is
$<7.0 \mathrm{~Hz}$ the whole carbody would vibrate violently from the centre to the carbody end, with a resonant peak appearing at about $6.2 \mathrm{~Hz}$. It can be also seen that the damping ratio has some effects on attenuating the resonant peak values. When the damping ratio increases from 1.5 to 5 per cent the largest ride index value can be decreased by about 13 per cent. Experimental results show that the carbody damping ratio of a fully equipped passenger vehicle in China is usually about 1.5-3 per cent. Higher damping ratio than that would require application of new materials, techniques, and designs, which till now seems to be a difficult area.

An obvious alternative for increasing the damping ratio in order to suppress the flexural vibration of a carbody, which can be seen clearly in Figs 5 and 6, is to increase the first bending frequency of the carbody. Figures 5 and 6 show that, when the first bending frequency is $>10 \mathrm{~Hz}$, the ride quality at a flexible carbody end is almost the same as that of a rigid one, even when the damping ratio is zero, and the ride quality at the middle of a flexible one would gradually approach to the value of a rigid carbody with the increase of the bending frequency. It also shows that the Sperling index will be not $>2.5$ when the damping ratio is 1.5 per cent and the bending frequency is $>7.5 \mathrm{~Hz}$, which means ride quality is satisfactory and the flexibility of the carbody can be considered to have no influences on ride comfort. It can be seen in Fig. 7 that when the bending frequency is as low as $6.5 \mathrm{~Hz}$ and the damping ratio is zero, the power percentage of the carbody flexural vibration increases greatly compared with Fig. 3. So it leads to the sharp increases of ride indices as shown in Figs 5 and 6. Figure 8 shows that for a typical passenger vehicle with the parameters given in Table 1 the ride quality indices of a flexible and rigid carbody will increase with the vehicle velocity and have the same trend. Though ride indices at the

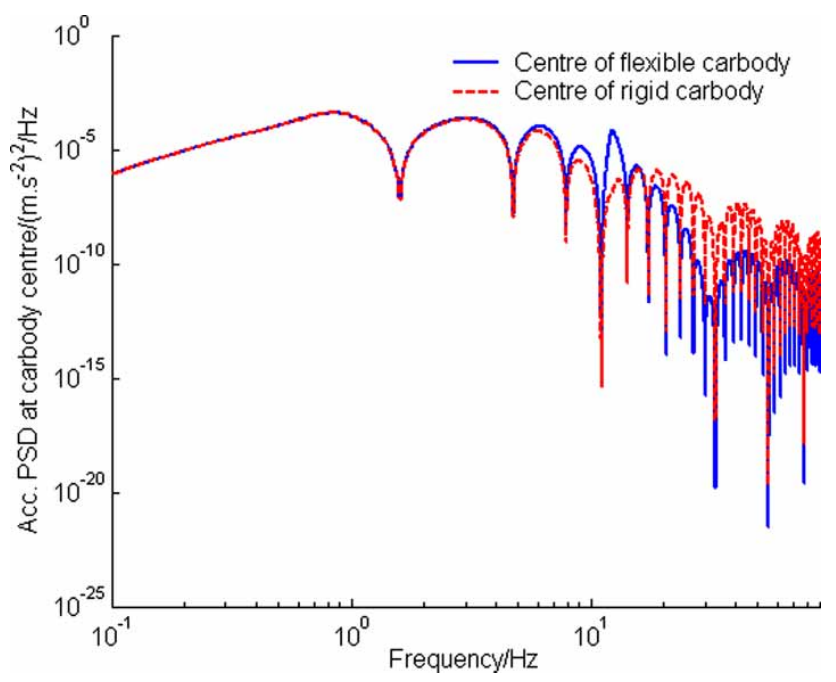

Fig. 3 Acceleration PSD at the carbody centre 


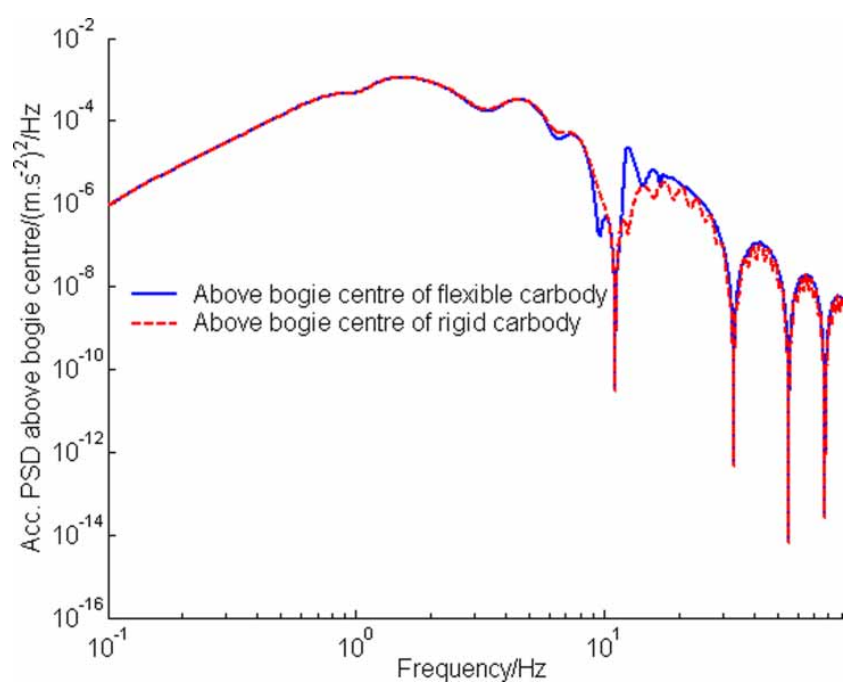

Fig. 4 Acceleration PSD above the bogie centre

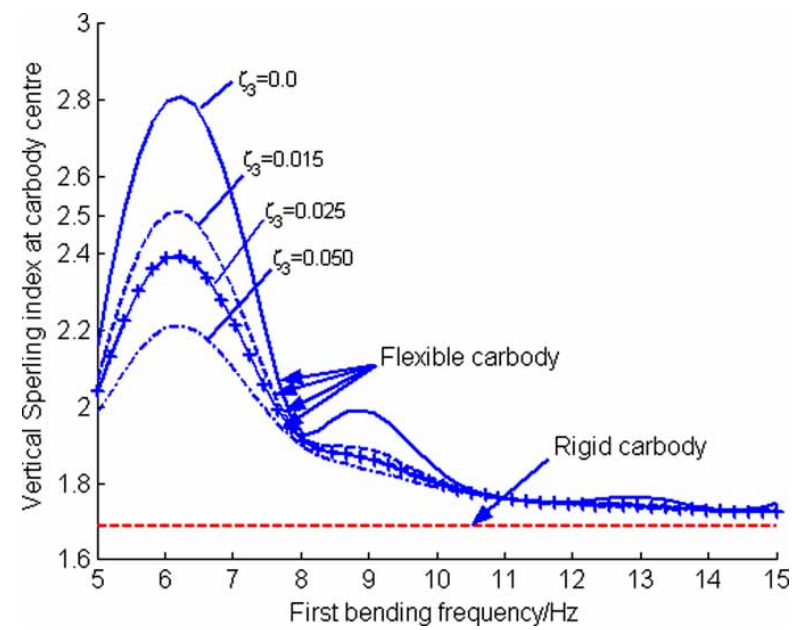

Fig. 5 Bending frequency versus ride quality at the carbody centre

centre of a flexible carbody are not as good as a rigid one, they all are $<2.5$ and the differences will not be well sensed by passengers, whereas the ride indices are almost the same at the end of rigid and flexible vehicles. So there is no necessity to take carbody flexibility into consideration in this case. This conclusion also holds true when the first bending frequency of the fully equipped vehicle is $>7.5 \mathrm{~Hz}$. Figures 5 and 6 also show that, when the bending frequency is $<7.0 \mathrm{~Hz}$, the ride index at carbody end already exceeds 2.8 so passive or active control measures should be taken to suppress the flexural vibration.

When changing running speed and still using the parameters in Table 1, the relations between the ride quality and the carbody stiffness are evaluated and illustrated in Figs 9 and 10. Similar to the results in Figs 5 and 6 , these show that when the bending frequencies get to certain values the ride indices at the carbody centre and above the bogie centre will reach

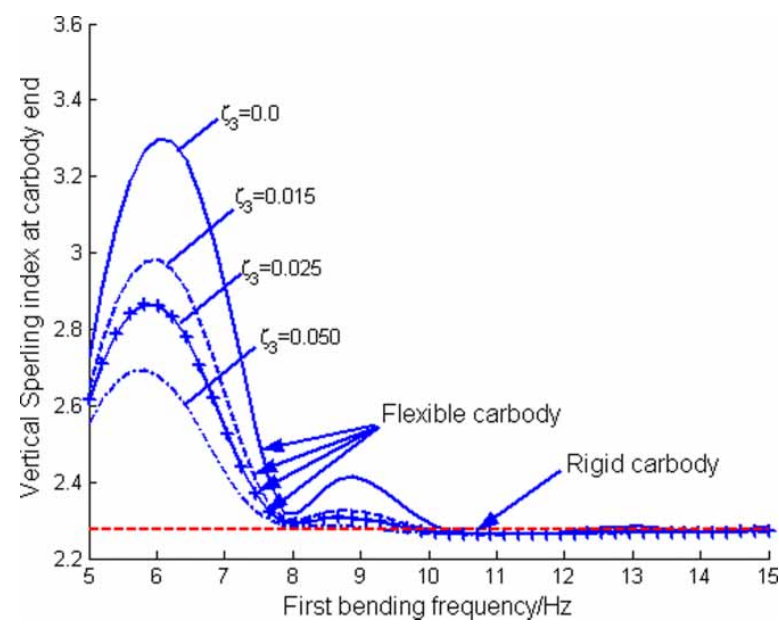

Fig. 6 Bending frequency versus ride quality at carbody end

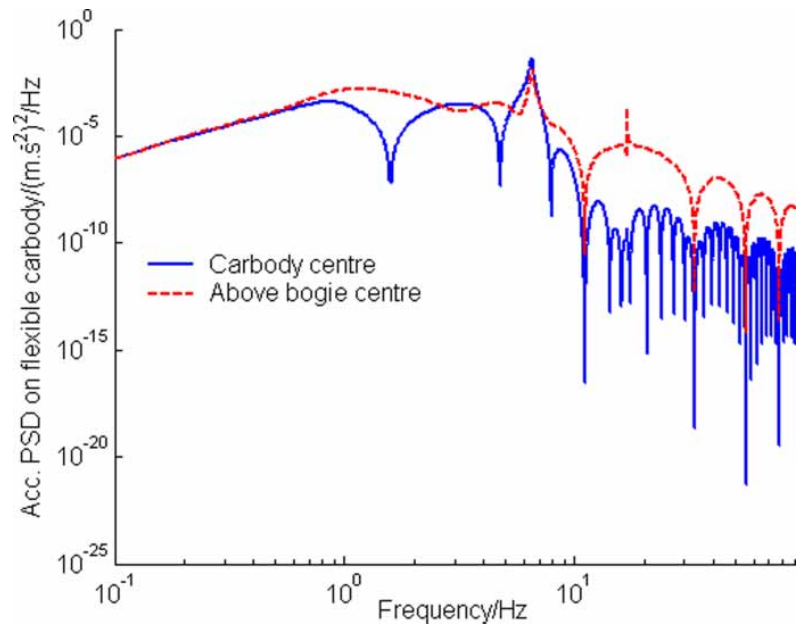

Fig. 7 Acceleration PSD of a low stiffness carbody

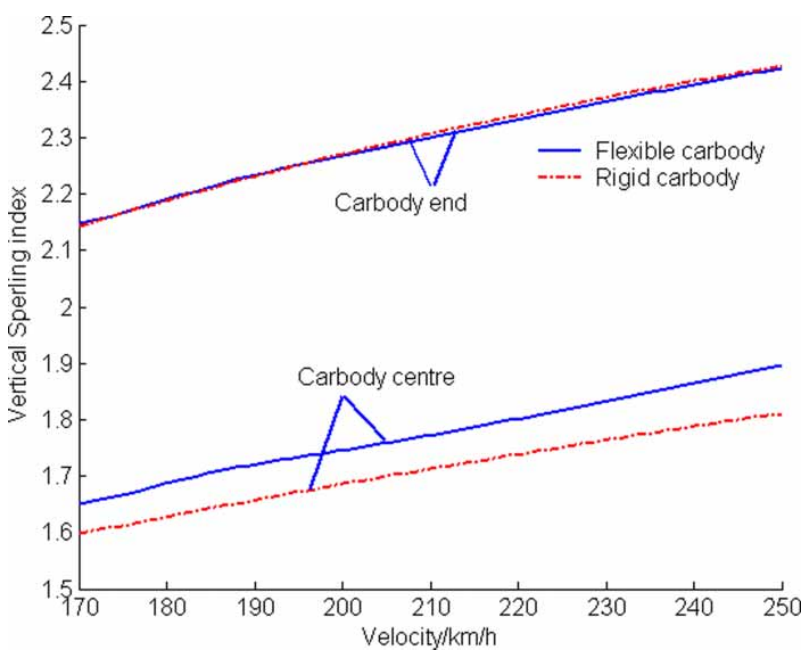

Fig. 8 Ride quality of rigid and flexible carbodies 


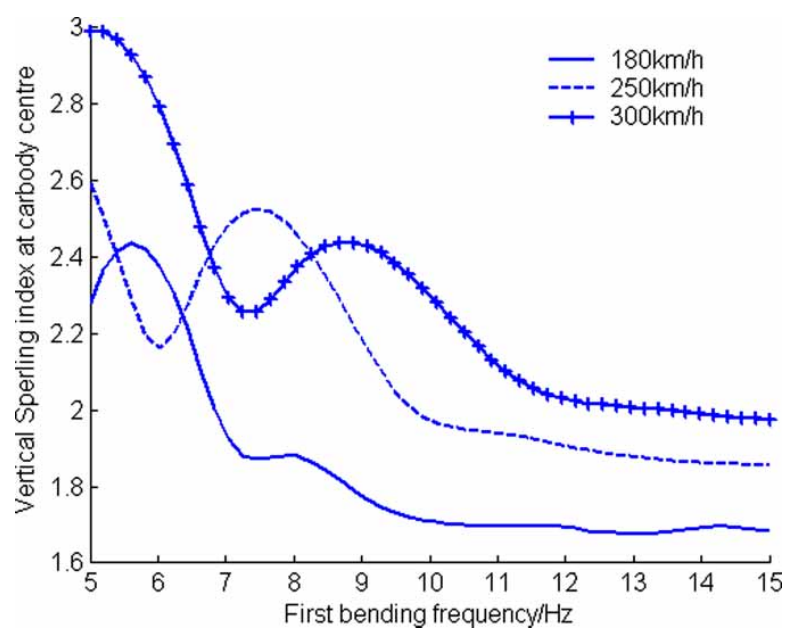

Fig. 9 Ride quality versus speed on the carbody centre

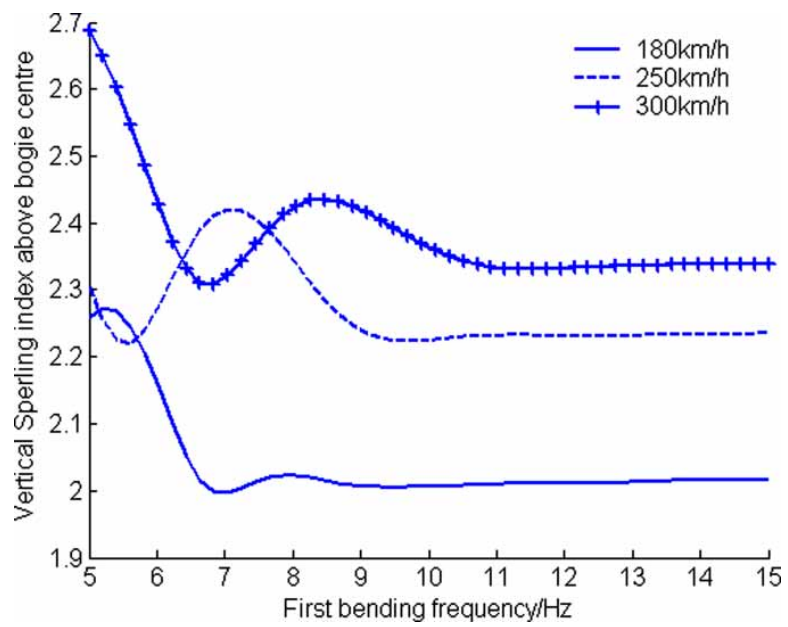

Fig. 10 Ride quality versus speed above the bogie centre

or approach to constant values, which are the values of rigid body ride quality indices. One can also find that the start frequency point, where the ride quality of a flexible carbody almost makes a negligible difference compared with that of a rigid one, increases with the running speed. This means the higher the vehicle velocity, the higher the stiffness of the carbody needs to be.

Generally it is very difficult to increase the bending frequency of an existing vehicle, and although active control techniques are definitely useful to suppress the rigid and flexural vibration of a carbody simultaneously if well designed, it will bring cost and complexity in maintenance and production. Since the bogies are the vibration sources of the carbody, curbing the vibration of bogies may be helpful to the carbody ride quality. Figures 11 and 12 illustrate the ride quality changes with the primary damper coefficients, which shows that higher primary damping reduces the vibration of the rigid and flexible carbody, although

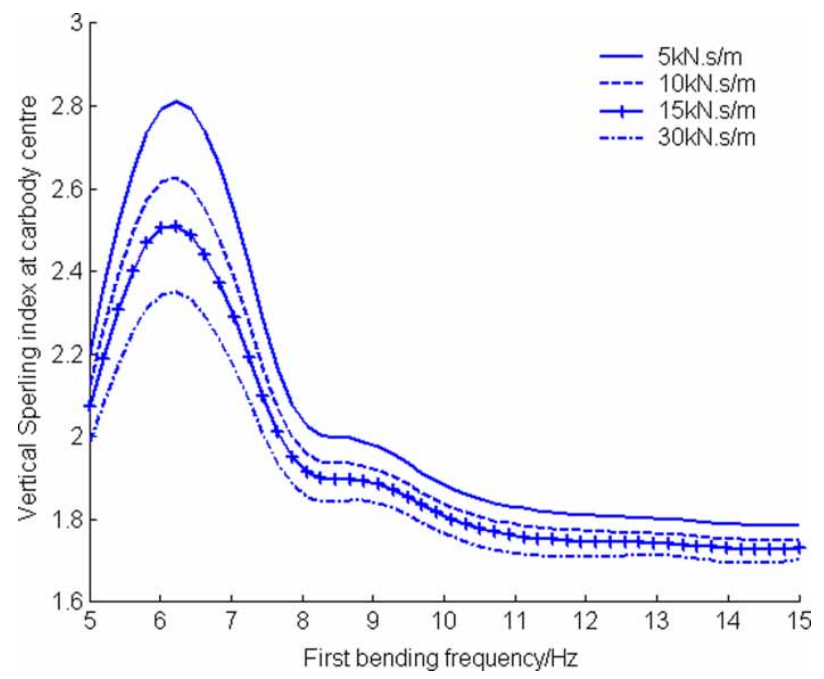

Fig. $11 c_{\mathrm{p}}$ effects on ride quality on the carbody centre

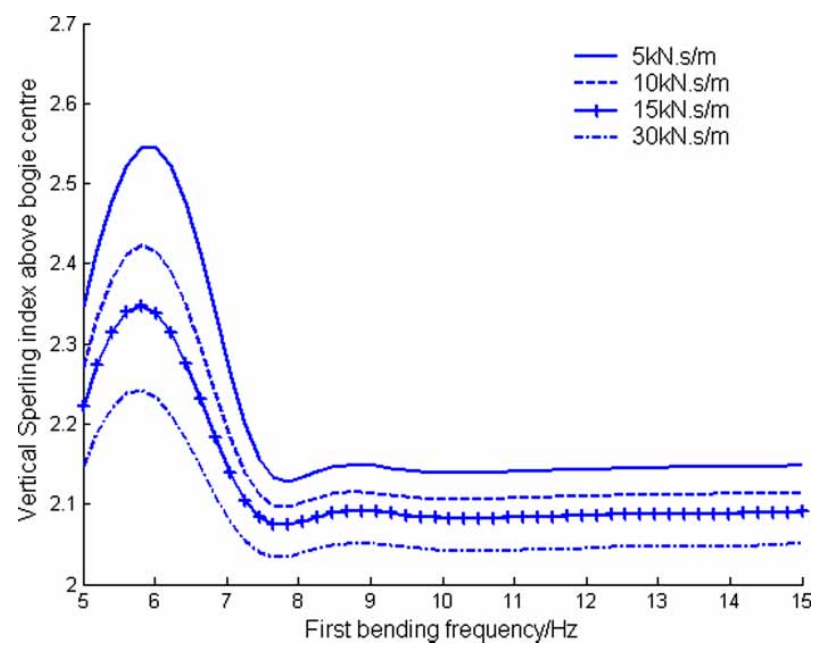

Fig. $12 c_{\mathrm{p}}$ effects on ride quality above the bogie centre

higher primary damper coefficient may deteriorate the maximum dynamic wheel-rail forces.

\subsection{Carbody resonant vibration analysis}

In Figs 5 and 6, it seems that the carbody resonant vibration happens because the first bending frequency approaches the damped bounce frequency of bogies. In order to assess this, the characteristics of bogie bounce modes are changed to $7.63 \mathrm{~Hz}$ damped frequency and 55.77 per cent damping ratio and the ride qualities are re-evaluated in Fig. 13. It shows that no resonant vibration happens near the bounce frequency of bogies, which is a different conclusion from what is generally accepted. Changing resonant frequency with train speed shown in Figs 9 and 10 suggests that the carbody flexural resonant vibration is primarily caused by changing nature of the track irregularities with the running speed of a railway 
vehicle arising from the so-called 'geometric filtering' effect caused by wheelbases and spacing between bogie centres, and this effect is described and analysed in Appendix 2. The carbody flexural vibration will be more strongly excited when the bending frequency approaches the excitation frequencies $f_{\mathrm{r}}=$ $n V /\left(2 l_{\mathrm{b}}\right)$, where $n$ is an integer number. Because of the 'wheelbase filtering' effect, the peak ride quality values do not happen precisely at the 'null pitch response' frequencies $f_{\mathrm{r}}=n V /\left(2 l_{\mathrm{b}}\right)$, and the exact resonant frequencies for carbody bounce modes can be obtained with numerical methods, which show that they are very near to the null pitch response frequencies as described in Appendix 2. If the carbody bending frequency coincides with one of those excitation frequencies at certain running speed, strong flexural resonant vibration of carbody will happen. When the vehicle speed is not so high, the carbody resonant vibration will not pose a problem as shown

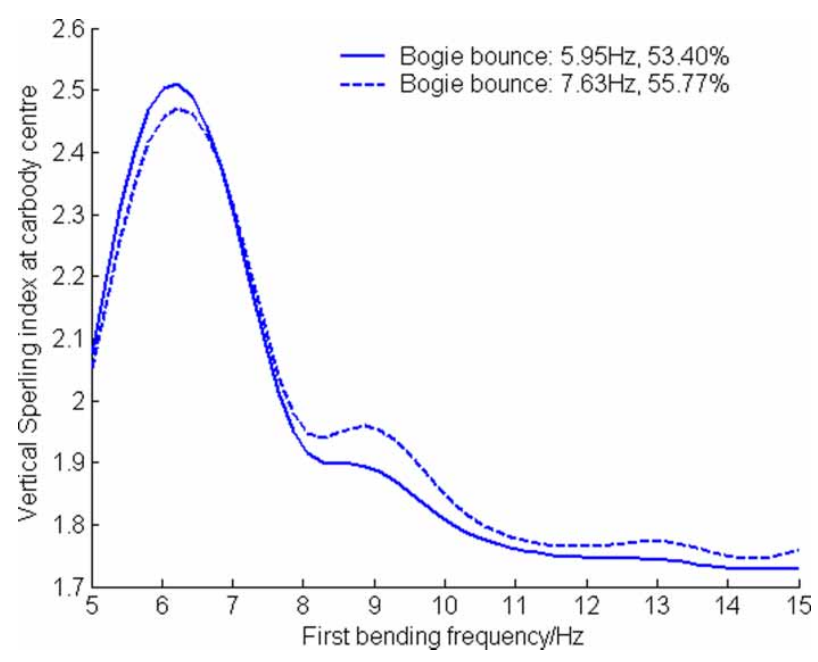

Fig. 13 Influences of bogie bounce frequency

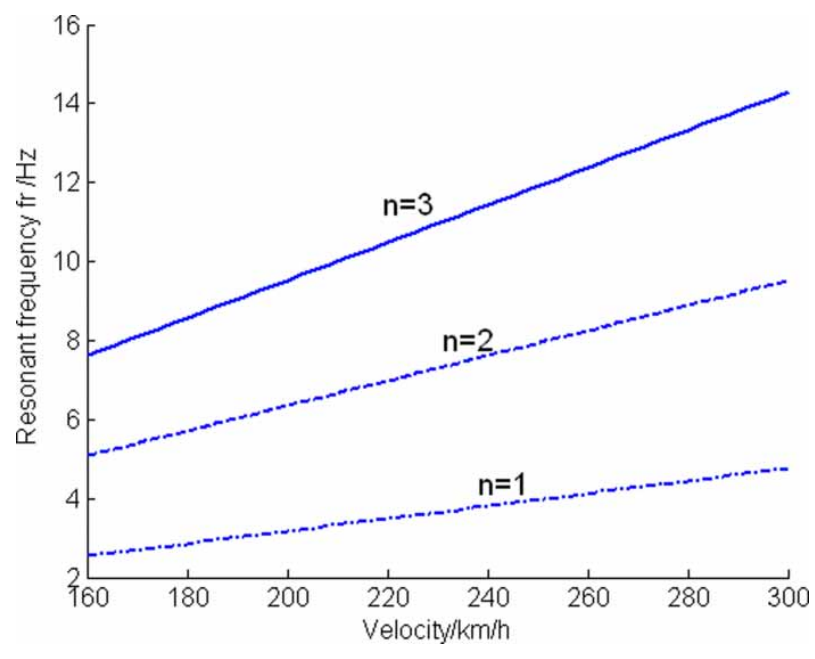

Fig. 14 Vehicle resonant frequencies in Figs 9 and 10, so the resonant frequencies approximately calculated with $f_{\mathrm{r}}=n V /\left(2 l_{\mathrm{b}}\right)$ are illustrated in Fig. 14 when the train speed is $>160 \mathrm{~km} / \mathrm{h}$ and $n$ changes from 1 to 3 . For a high speed track spectrum used in this study, when $n$ is $>2$ the track excitation power will become rather small (Fig. 2), so that it will be easily attenuated by carbody internal damping (Fig. 5) and will not cause great impact on ride comfort. The first bending frequency of a fully equipped vehicle usually will never be as low as the value shown in Fig. 14 when $n$ is equal to 1 . So significant resonant vibrations will usually happen when the bending frequency is near to the frequency $f_{\mathrm{r}}=V / l_{\mathrm{b}}$, i.e. $n=2$, as shown in Figs 9 and 10. For a particular vehicle design the maximum speed and bogie geometry are determined, so the only way to avoid resonant vibration is to increase carbody stiffness (Figs 9 and 10) if active techniques are not used.

\section{CONCLUSIONS}

With the covariance method and a simplified vertical model, the influences of carbody stiffness on the ride quality are studied. Results show lower limits for the bending frequency to avoid deterioration of vehicle ride quality: the higher the running speed of a vehicle the larger the bending frequencies must be. And the carbody flexibility can be considered to be largely irrelevant in terms of vertical ride quality when the bending frequency of the fully equipped vehicle is higher than the lower limits. Results also show that the flexural resonant vibration of carbody will not happen when the bending frequency of the carbody coincides closely with the bounce frequency of bogies, i.e. that the carbody resonant vibration is mainly caused directly by the geometric filtering phenomena rather than bogie bounce, considering the bogie bounce damping ratio of a typical high-speed passenger vehicle is usually rather high as the one in this study. And a calculation method of the carbody flexural resonant frequencies is presented according to the geometric filtering analysis.

The next stage of this research is to incorporate a carbody FEM model into a vehicle multi-body model. This will be used to verify the conclusions and determine additional effects arising from other more complex carbody modes, e.g. the torsion and/or diagonal torsion modes.

(C) Authors 2009

\section{REFERENCES}

1 Morimur, T. and Seki, M. The course of achieving $270 \mathrm{~km} / \mathrm{h}$ operation for Tokaido Shinkansen - Part 1: technology and operations overview. Proc. IMechE, 
Part F: J. Rail and Rapid Transit, 2005, 219(F1), 21-26. DOI: 10.1243/095440905X8781.

2 Carlbom, P. Carbody and passengers in rail vehicle dynamics. Doctoral Dissertation, Royal Institute of Technology, Sweden, 2000.

3 Carlbom, P. Combining MBS with FEM for rail vehicle dynamics analysis. Multibody Syst. Dyn., 2001, 6, 291300.

4 Diana, G., Cheli, F., Andrea, C., Corradi, R., and Melzi, S. The development of a numerical model for railway vehicles comfort assessment through comparison with experimental measurements. Veh. Syst. Dyn., 2002, 38(3), 165-183.

5 Hac, A. Stochastic optimal control of vehicle with elastic body and active suspension. J. Dyn. Syst. Meas. Control, 1986, 108(3), 106-110.

6 Wu, P. B. and Zeng, J. Dynamic response analysis of railway passenger car with flexible carbody model based on the semi-active suspension. Veh. Syst. Dyn., 2004, 41(Suppl.), 774-783.

7 Foo, E. and Goodall, R. M. Active suspension control of flexible-bodied railway vehicle using electro-hydraulic and electromagnetic actuators. Control Eng. Pract., 2000, 8, 507-518.

8 Takigami, T. and Tomioka, T. Investigation to suppress bending vibration of railway vehicle carbodies using piezoelectric elements. Q. Rep. RTRI, 2005, 46(4), 225-230.

9 Schandl, G., Lungner, P., Benatzky, C., Kozek, M., and Stribersky, A. Comfort enhancement by an active vibration reduction system for a flexible railway car body. Veh. Syst. Dyn., 2007, 45(9), 835-847.

10 Suzuki, Y. and Akutsu, K. Theoretical analysis of flexural vibration of car body. Q. Rep. RTRI, 1990, 31(1), $42-48$.

11 Goodall, R. M., Pearson, J. T., and Pratt, I. Design of complex controllers for active secondary suspension on railway vehicle. In Proceeding of the 14th IAVSD Symposium on Vehicle system dynamics, Michigan, USA, 1995, suppl. 25, pp. 217-228.

12 Pratt, I. Active suspension applied to railway trains. Dissertation, Loughborough University, 1996.

13 Schupp, G. Simulation of railway vehicles: necessities and applications. Mech. Based Des. Struct. Mach., 2003, 31(3), 297-314.

14 Wang, F. T., Zhou, J., and Ren, L. H. Analysis on track spectrum density for dynamic simulations of high-speed vehicles (in Chinese). J. China Railw. Soc., 2002, 24(5), 21-27.

15 Kim, Y.-G., Kwon, H.-B., Kim, S.-W., Park, C.-K., and Kim, T.-W. Correlation of ride comfort evaluation methods for railway vehicles. Proc. IMechE, Part F: J. Rail and Rapid Transit, 2003, 217(F2), 73-87. DOI: 10.1243/095440903765762823.

16 Muller, P. C., Popp, K., and Schiehlen, W. O. Covariance analysis of nonlinear stochastic guideway. In Proceedings of the 6th IAVSD Symposium on Vehicle systems dynamics, September 1979, pp. 337-351.

17 Paddison, J. E. Advanced control strategies for maglev suspension systems. Doctoral Dissertation, Loughborough University, UK, 1995.

18 Zhou, J., Shen, G., Zhang, H., and Ren, L. Application of modal parameters on ride quality improvement of

railway vehicles. Veh. Syst. Dyn., 2008, 46(1) (Suppl), 629-641.

19 Garg, V. K. and Dukkipati, R. V. Dynamics of railway vehicle systems, 1984 (Academic Press, New York).

20 International Organization for Standardization. Mechanical vibration and shock-evaluation of human exposure to whole body vibration - part 1: general requirements, ISO 2631-1:1997, 1997.

21 Zuo, L. and Nayfeh, S. A. Low order continuous-time filters for approximation of the ISO 2631-1 human vibration sensitivity weightings. J. Sound Vibr., 2003, 265(2), 495-465.

\section{APPENDIX 1}

\section{Notation}

$a$

$A_{\mathrm{V}}$

$c_{\mathrm{p}}$

$c_{\mathrm{S}}$

C

$\mathbf{D}_{\mathrm{w}}, \mathbf{D}_{\mathrm{dw}}$

E

$f_{r}$

$G_{\mathrm{v}}(s)$

$G_{\mathrm{s}}(s)$

I

$I_{\mathrm{b}}, I_{\mathrm{t}}$

$k_{\mathrm{p}}$

$k_{\mathrm{s}}$

K

$l_{1}, l_{2}$

$l_{\mathrm{b}}$

$l_{\mathrm{w}}$

L

$L_{\mathrm{r}}$

$m_{\mathrm{b}}, m_{\mathrm{t}}$

M

$n$

$P_{1}, P_{2}$

$q_{i}(t)$

$S_{\mathrm{v} \Omega}, S_{\mathrm{v} \omega}$

$S_{\Omega}, S_{\omega}$

$t$

V

$x$

$y$ amplitude of track irregularity wavelength track excitation intensity coefficient primary damping coefficient per axle secondary damping coefficient per bogie damping matrix track displacement and velocity input matrices Elasticity modulus null response frequency shaping filter of the track vertical unevenness vertical perception filter for Sperling index beam moment of inertia carbody and bogie frame pitch inertia primary spring stiffness per axle secondary spring stiffness per bogie stiffness matrix the positions where the secondary suspension forces act referred to the carbody left end half of bogie centres half of bogie wheel base carbody length track irregularity wavelength mass of carbody and bogie frame inertia matrix integer number suspension forces acted on carbody by bogie 1 and bogie 2 modal coordinate spatial and time domain PSD of vertical track irregularity spatial and time domain PSDs of vertical track irregularity respectively time variable vehicle running speed position coordinate along carbody system response vector 
$Y_{i}(x) \quad i$ th mode shape function

$z_{\mathrm{b}}, z_{\mathrm{t} 1}, z_{\mathrm{t} 2} \quad$ carbody, bogie 1 and bogie 2 vertical displacement

$z_{w 1}, z_{w 2}$, track vertical irregularities experienced

$z_{w 3} z_{w 4} \quad$ by wheelset respectively

$z_{w} \quad$ track unevenness vector

$\beta_{1}, \beta_{2}, \beta_{3} \quad$ phase lags with respect to the first wheelset

$\delta(x) \quad$ Dirac delta function

$\theta_{\mathrm{b}}, \theta_{\mathrm{t} 1}, \theta_{\mathrm{t} 2} \quad$ carbody, bogie 1 and bogie 2 pitch

angle

$\mu \quad$ internal damping coefficient

$\xi_{3}, \xi_{4} \quad$ first and second bending mode

damping ratio

$\rho \quad$ carbody mass of per unit length

$\omega \quad$ angular frequency

$\omega_{3}, \omega_{4} \quad$ first and second bending mode

frequency

$\Omega_{c}, \Omega_{r} \quad$ cut-off frequencies

\section{APPENDIX 2}

\section{Geometry filter analysis}

A simplified model is used in the geometry filter analysis as shown in Fig. 15, which is obtained from omitting the primary suspension and dynamics of the two bogie frames in the Fig. 1 model.

It is assumed that the track irregularity consists of sinusoidal waves, so the irregularities experienced by each wheelset are

$$
\begin{aligned}
& z_{w 1}=a \sin \omega t \quad z_{w 2}=a \sin \left(\omega t-\beta_{1}\right) \\
& z_{w 3}=a \sin \left(\omega t-\beta_{2}\right) \quad z_{w 4}=a \sin \left(\omega t-\beta_{2}\right)
\end{aligned}
$$

where $\omega=2 \pi V / L_{\mathrm{r}}, \quad \beta_{1}=4 \pi l_{\mathrm{w}} / L_{\mathrm{r}}, \quad \beta_{2}=4 \pi l_{\mathrm{b}} / L_{\mathrm{r}}$, and $\beta_{3}=2 \pi\left(2 l_{\mathrm{w}}+2 l_{\mathrm{b}}\right) / L_{\mathrm{r}}, L_{\mathrm{r}}$ is wavelength of track input.
The displacements at mid-points of front and rear bogie are

$$
\begin{aligned}
& z_{1}=\frac{1}{2}\left(z_{w 1}+z_{w 2}\right)=a \sin \left(\omega t-\frac{\beta_{1}}{2}\right) \cos \frac{\beta_{1}}{2} \\
& z_{2}=\frac{1}{2}\left(z_{w 2}+z_{w 3}\right)=a \sin \left(\omega t-\beta_{2}-\frac{\beta_{1}}{2}\right) \cos \frac{\beta_{1}}{2}
\end{aligned}
$$

The vehicle dynamic equation of Fig. 15 model can be obtained as

$$
\begin{aligned}
& m_{\mathrm{b}} \ddot{z}_{\mathrm{b}}+2 c_{\mathrm{s}} \dot{z}_{\mathrm{b}}+2 k_{\mathrm{s}} z_{\mathrm{b}}=k_{\mathrm{s}}\left(z_{1}+z_{2}\right)+c_{\mathrm{s}}\left(\dot{z}_{1}+\dot{z}_{2}\right) \\
& I_{\mathrm{b}} \ddot{\theta}_{\mathrm{b}}+2 c_{\mathrm{s}} l_{\mathrm{b}}^{2} \dot{\theta}_{\mathrm{b}}+2 k_{\mathrm{s}} l_{\mathrm{b}} \theta_{\mathrm{b}}=k_{\mathrm{s}} l_{\mathrm{w}}\left(z_{2}-z_{1}\right)+c_{\mathrm{s}} l_{\mathrm{w}}\left(\dot{z}_{2}-\dot{z}_{1}\right)
\end{aligned}
$$

From equations (26) and (27), one can see that the vibration of the simplified symmetrical vehicle system in Fig. 15 can be considered to be composed of two SDOF systems, one is carbody bounce mode, another is pitch mode. And the $z_{1}+z_{2}$ and $z_{2}-z_{1}$ are the inputs for the bounce and pitch modes, respectively.

Combining the bounce and pitch inputs for carbody, one has

$$
\begin{aligned}
& z_{1}+z_{2}=2 a \cos \frac{2 \pi l_{\mathrm{w}}}{L_{\mathrm{r}}} \cos \frac{2 \pi l_{\mathrm{b}}}{L_{\mathrm{r}}} \sin \left(\frac{2 \pi V}{L_{\mathrm{r}}} t-\frac{\beta_{3}}{2}\right) \\
& z_{2}-z_{1}=-2 a \cos \frac{2 \pi l_{\mathrm{w}}}{L_{\mathrm{r}}} \sin \frac{2 \pi l_{\mathrm{b}}}{L_{\mathrm{r}}} \cos \left(\frac{2 \pi V}{L_{\mathrm{r}}} t-\frac{\beta_{3}}{2}\right)
\end{aligned}
$$

So when

$$
L_{\mathrm{r}}=\frac{4 l_{\mathrm{w}}}{2 n+1}, \quad n=0,1, \ldots
$$

the track inputs to pitch and bounce modes are all zeros, in other word, that there will be no pitch and bounce responses at $f_{\mathrm{r}}=V(2 n+1) / 4 l_{\mathrm{w}}$. Therefore, this phenomenon is called as the 'wheelbase filter' effect.

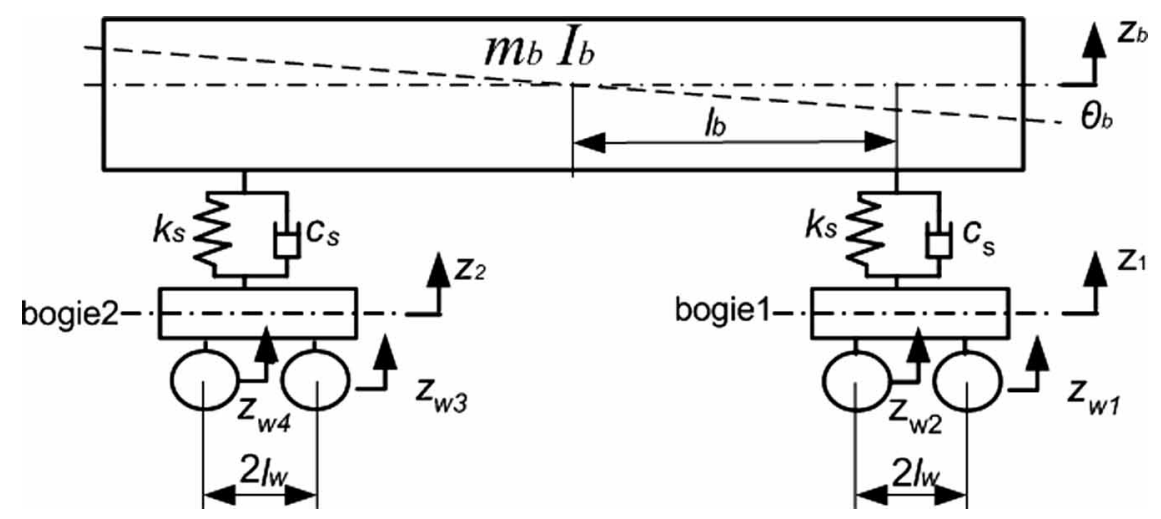

Fig. 15 Simplified vehicle model 
When

$$
L_{\mathrm{r}}=\frac{4 l_{\mathrm{b}}}{2 n+1}, \quad n=0,1, \ldots
$$

the track input to bounce mode is zero, i.e. there will be no forced bounce response when $f_{\mathrm{r}}=V(2 n+1) / 4 l_{\mathrm{b}}$.

When

$$
L_{\mathrm{r}}=\frac{2 l_{\mathrm{b}}}{n}, \quad n=1,2, \ldots
$$

the track input to carbody pitch is zero, i.e. there will be no forced pitch response when $f_{\mathrm{r}}=n V / 2 l_{\mathrm{b}}$. These are called as the 'bogie spacing filtering' effects.

According to equations (28) and (29), define track excitation input gains for bounce and pitch vibrations are

$$
\begin{aligned}
T_{\mathrm{b}} & =\left|\cos \frac{2 \pi l_{\mathrm{w}}}{L_{\mathrm{r}}} \cos \frac{2 \pi l_{\mathrm{b}}}{L_{\mathrm{r}}}\right| \\
& =\left|\cos \left(\frac{2 \pi l_{\mathrm{w}}}{V} f_{\mathrm{r}}\right) \cos \left(\frac{2 \pi l_{\mathrm{b}}}{V} f_{\mathrm{r}}\right)\right| \\
T_{\mathrm{p}} & =\left|\cos \frac{2 \pi l_{\mathrm{w}}}{L_{\mathrm{r}}} \sin \frac{2 \pi l_{\mathrm{b}}}{L_{\mathrm{r}}}\right| \\
& =\left|\cos \left(\frac{2 \pi l_{\mathrm{w}}}{V} f_{\mathrm{r}}\right) \sin \left(\frac{2 \pi l_{\mathrm{b}}}{V} f_{\mathrm{r}}\right)\right|
\end{aligned}
$$

where $f_{\mathrm{r}}=V / L_{\mathrm{r}}$ is the track excitation frequency. When the vehicle running speed is $200 \mathrm{~km} / \mathrm{h}$ and the parameters in Table 1 are used, the input gains of bounce and pitch mode are shown in Fig. 16.
From Fig. 16 one can find that input gains for bounce mode are very near to its local maximum values when the input gains for pitch mode are zero at $f_{\mathrm{r}}=n V / 2 l_{\mathrm{b}}$, and it holds true also for the pitch input gains. For example, when the track excitation $f_{\mathrm{r}}$ is equal to $6.3492 \mathrm{~Hz}$ as shown in Fig. 16, the pitch input gain, $T_{\mathrm{p}}$, is zero whereas the maximum bounce gain value $T_{\mathrm{b}}$ happens at $f_{\mathrm{r}}=6.1785 \mathrm{~Hz}$, which can be obtained with numerical methods with the equation (33) as the goal function. So if bending frequency of carbody coincides with the frequencies with maximum input gains for bounce mode, violent resonant flexural vibration will happen.

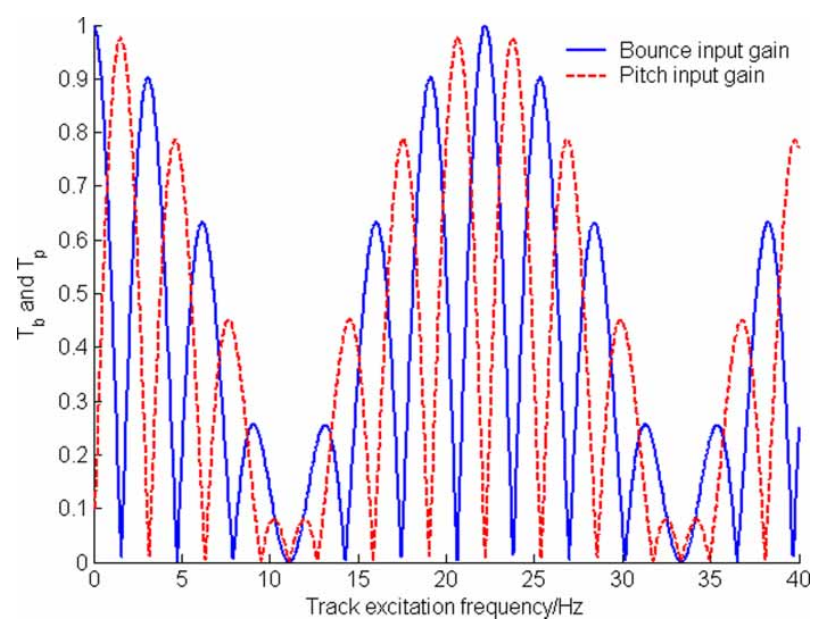

Fig. 16 Gain of bounce and pitch modes input 